\title{
SISTEM DUKUNGAN SOSIAL BAGI KORBAN EKSPLOITASI SEKSUAL KOMERSIAL ANAK (ESKA)
}

\section{SOCIAL SUPPORT SYSTEM FOR THE VICTIMS OF COMMERCIAL SEXUAL EXPLOITATION OF CHILDREN (CSEC)}

\author{
Muthia Fadhila Khairunnisa ${ }^{1}$, Nurliana Cipta Apsari ${ }^{2}$ \\ 1,2Program Studi IImu Kesejahteraan Sosial FISIP Universitas Padjadjaran \\ muthia18001@mail.unpad.ac.id', nurliana.cipta.apsari@unpad.ac.id
}

\begin{abstract}
Risk factors such as maltreatment, academic failure, less support from family, friendship, less attachment with parent and sexual relationship experience in early age are factors which make someone vulnerable to be a victim of Commercial Sexual Exploitation of Children (CSEC). Trauma that they got after becoming the victim and risky environment can negatively affect the child's biopsychosocial development. This article focuses on the attempt to build a social support system as an intervention method to minimzr the risk factors and increase the protective factors. This literature review on CSEC uses the social ecological model to know the roles of family or caregiver, community, and culture and society as a social support system for the victim. The result shows that acceptance, protection, and empowerment are the keys to social support for victims of CSEC. Good synergy between three levels of the system can create a maximal result. Social worker is needed as a supervisor to enhance the quality and sustainability of the social support.
\end{abstract}

Keywords: commercial sexual exploitation, children, social support, social ecological model

\section{ABSTRAK}

Faktor-faktor resiko seperti perlakuan salah, kegagalan di bidang akademik, tidak mendapatkan dukungan dari keluarga, pergaulan teman sebaya, kurangnya kelekatan dengan figure orang tua dan pengalaman hubungan seksual di usia dini merupakan faktor yang membuat seseorang rentan menjadi korban Eksploitasi Seksual Komersial Anak (ESKA). Trauma yang didapat setelah menjadi korban serta lingkungan yang berisiko bisa berdampak negatif pada perkembangan biopsikososialnya. Artikel ini berfokus pada upaya membangun sistem dukungan sosial sebagai metode intervensi untuk meminimalisasi faktor risiko dan meningkatkan faktor perlindungan. Studi literatur tentang ESKA ini menggunakan model sosial ekologi untuk mengetahui peran keluarga atau pengasuh, komunitas, serta budaya dan masyarakat luas sebagai sistem dukungan sosial bagi korban. Hasil kajian menunjukkan bahwa system penerimaan, system perlindungan, dan system pemberdayaan merupakan kunci dari dukungan sosial bagi korban ESKA. Sinergi yang baik antara ketiga tingkatan sistem dapat memberikan hasil yang maksimal. Pekerja sosial dibutuhkan sebagai supervisi yang bisa meningkatkan kualitas dan keberlanjutan dukungan sosial.

Kata kunci: eksploitasi seksual komersial, anak, dukungan sosial, model sosial ekologi

\section{PENDAHULUAN}

Kasus eksploitasi seksual anak semakin hari semakin marak terjadi di Indonesia. Terdapat 150 kasus yang berkaitan dengan eksploitasi seksual anak terjadi di Indonesia sepanjang tahun 2018 yang terpantau di media (ECPAT Indonesia, 2019). Kasus-kasus tersebut meliputi pornografi anak, prostitusi anak, perdagangan anak untuk seksual, perkawinan anak, prostitusi anak online, grooming, serta seks anak di tempat pariwisata, dan melibatkan sebanyak 379 anak sebagai korban, 153 di antaranya merupakan korban prostitusi anak. KPAI mencatat anak-anak menjadi korban perdagangan orang dijebak melalui media sosial (KPAI, 2019). 


\begin{tabular}{|c|c|c|c|c|}
\hline Share: Social Work Jurnal & VOLUME: 10 & NOMOR: 2 & HALAMAN: 57 - 63 & $\begin{array}{c}\text { ISSN: } 2339-0042(p) \\
\text { ISSN: } 2528-1577(e) \\
\text { DOI: } 10.24198 / \text { share.v10i1.26896 }\end{array}$ \\
\hline
\end{tabular}

Istilah Eksploitasi Seksual Komersial Anak, atau ESKA, dijelaskan dalam Deklarasi Kongres Dunia Menentang Eksploitasi Seksual Komersial Anak di Stockholm tahun 1996 sebagai, "Kekerasan seksual oleh orang dewasa dan pemberian imbalan dalam bentuk uang tunai atau barang terhadap anak, atau orang ketiga, atau orang-orang lainnya. Anak tersebut diperlakukan sebagai sebuah objek seksual dan sebagai objek komersial, dan merupakan sebuah bentuk pemaksaan dan kekerasan terhadap anak serta mengarah pada bentuk-bentuk kerja paksa atau perbudakan modern". Berbeda dengan kekerasan seksual pada anak, ESKA berorientasi pada tujuan untuk mendapat keuntungan, baik berupa barang atau jasa.

Korban ESKA masuk pada kategori anak yang membutuhkan perlindungan khusus (children in need of special protection) karena berada di kondisi rentan. Dalam laporan UNICEF yang berjudul Hidden in Plain Sight (2014), tidak ada faktor memadai yang dapat menjelaskan mengapa anak-anak berisiko menjadi korban kekerasan seksual, walaupun jelas mereka lebih rentan terhadap pelecehan karena usia mereka. Risiko terhadap kerentanan mereka dapat berbeda, tergantung dari tahap perkembangannya. Anak kecil dapat lebih rentan terhadap kekerasan yang dilakukan oleh pengasuh atau orang yang mereka percayai. Sementara, remaja cenderung lebih rentan menjadi korban di luar rumah melalui interaksi dengan teman sebaya maupun orang asing.

Praktik ESKA merupakan pelanggaran terhadap hak anak, yakni hak anak untuk mendapat perlindungan. Anak-anak yang sedang dalam masa pertumbuhan dan terjumus dalam praktik berbahaya ini bisa mengalami hambatan dalam perkembangan biologis, psikologis, maupun sosialnya. Secara biologis, seorang anak berisiko terkena Infeksi Menular Seksual (IMS), HIV/AIDS, atau mengalami kekerasan fisik (ECPAT Internasional, 2006). Psikologis anak juga dapat terganggu akibat paksaan serta tindakan kekerasan yang berdampak pada ketidakstabilan emosional sang anak. Anak cenderung merasa tidak percaya diri, putus asa, depresi, sehingga keberfungsian atau kemampuan berinteraksi dengan lingkungan sosialnya pun menurun.

Penelitian yang sudah dilakukan sebelumnya menemukan keterkaitan antara pengalaman kekerasan seksual sejak dini dengan perilaku yang negatif. Strategi coping umum yang diadopsi oleh anak seperti kabur dari rumah, bolos sekolah, melakuksan praktik hubungan berisiko, menggunakan narkoba atau alkohol, dapat mengisolasi mereka secara sosial serta menempatkan mereka pada risiko pelecehan atau eksploitasi lebih lanjut di masa depan (Dinwiddie, et al., 2000). Jika tidak dilakukan intervensi, tingkat intensitas maupun jangkauan penyimpangan tersebut bisa menjadi lebih luas. Akan tetapi, anak-anak yang menjadi korban ESKA pada umumnya mengalami ketakutan untuk kembali kedalam keluarga maupun lingkungannya karena dalam keluarga maupun lingkungan tersebut akan muncul stigma negatif tentang anak tersebut (Sugiharti, 2017). Sementara itu, penelitian yang dilakukan oleh Liyawati \& Imron (2016) menemukan bahwa anak korban ESKA mengalami eksklusi dalam 3 bidang, yaitu layanan, kebijakan dan penerimaan sosial.

Kajian literatur oleh Goatley (2012) mengungkapkan adanya artikel ilmiah yang membahas tentang dukungan sosial di kalangan pekerja seks komersial mengidentifikasi penggunaan dukungan sosial sebagai keterampilan coping bagi para pekerja. Artikel lain oleh Dalla et al. (2003) menunjukkan bahwa dukungan sosial merupakan hal penting bagi keterampilan pekerja seks komersial untuk menjadi pribadi yang resilien begitu ia terpapar dengan kekerasan. Banyak perempuan dalam artikel tersebut yang menyatakan bahwa kekerasan merupakan risiko pekerjaan, namun jaringan dukungan sosial membantu mereka untuk mengatasi trauma.

Walsh dalam Hutchison (2015) mengkategorikan sumber daya dukungan sosial menjadi tiga: (1) Dukungan material, berupa sandang, pangan, papan; (2) Dukungan emosional, berupa dukungan interpersonal; (3) Dukungan instrumental, berupa pelayanan yang disediakan oleh kontak kasual, seperti, pedagang atau tuan tanah. Dukungan sosial bisa didefinisikan sebagai interaksi dan hubungan interpersonal yang menyediakan pertolongan atau rasa keterikatan kepada orang-orang yang kita anggap peduli (Hobfoll, 1996; Hutchison, 2015). Kajian Zimet, Dahlem, Zimet, \& Farley dalam Goatley (2012) mendefinisikan dukungan sosial sebagai komunitas, hubungan keluarga dan hubungan sosial yang menjadi andalan korban sebagai sistem dorongan, kepercayaan diri, dan kekuatan.

Penyusunan artikel ini bertujuan untuk menggambarkan sistem dukungan sosial (social support system) untuk korban ESKA dalam menghadapi dampak negatif yang dialami, terutama apabila anak mengalami kesulitan melakukan reintegrasi kepada pihak keluarga maupun lingkungan oleh pekerja sosial yang salah 


\begin{tabular}{|c|c|c|c|c|}
\hline Share: Social Work Jurnal & VOLUME: 10 & NOMOR: 2 & HALAMAN: 57 - 63 & $\begin{array}{c}\text { ISSN: } 2339-0042(p) \\
\text { ISSN: } 2528-1577(e) \\
\text { DOI: } 10.24198 / \text { share.v10i1.26896 }\end{array}$ \\
\hline
\end{tabular}

satu fokus intervensi nya adalah perlindungan anak.

\section{METODE}

Metode yang digunakan dalam kajian ini adalah studi kepustakaan (library research). Studi kepustakaan merupakan suatu studi yang digunakan dalam mengeumpulkan informasi dan data dengan bantuan berbagai macam material yang ada di perpustakaan seperti dokumen, buku, majalah, kisah-kisah sejarah, dan sebagainya (Mardalis, 1999).

Kajian literatur ini ditinjau menggunakan pendekatan perspektif sistem. Perspektif ini melihat perilaku manusia sebagai hasil dari interaksi di dalam dan di antara sistem-sistem yang saling terkait. Payne (2014) menggambarkan perspektif system bagi seorang pekerja sosial adalah mengintegrasikan pemberian pertolongan individual dengan intervensi-intervensi yang juga melibatkan keluarga, masyarakat dan Lembaga sebagai sebuah system yang berkaitan. Perspektif system memusatkan perhatiannya pada hubungan antara sumber daya- sumber daya yang dimiliki oleh keluarga dan kelompok serta menjembatani agar sumber daya yang dimiliki dapat dimanfaatkan seluas-luasnya untuk membantu individual (Payne, 2014). Model yang dijadikan dasar kajian ini adalah social ecological model, yang berfokus pada hubungan dan interaksi antara makhluk hidup dengan lingkungannya; menaruh tekanan pada interdependensi dan mutual influence. Social ecological model dapat memberi ilustrasi terkait pentingnya jaringan orang dan struktur yang mengelilingi anak, menjaga kesejahteraan mereka, dan mendukung perkembangan optimal mereka (United Nations Children's Fund, 2018). Model ini secara berurutan mengkategorikan keluarga/pengasuh, komunitas, serta budaya dan masyarakat sebagai aspek-aspek yang memengaruhi perkembangan anak. Dalam kajian ini, social ecological model digunakan untuk melihat lingkungan sekitar anak sebagai sistem dukungan sosial, atau social support system.

Referensi dan data yang digunakan berasal dari berbagai organisasi yang bergerak dalam penanggulangan isu ESKA atau bidang perlindungan anak, seperti, End Child Prostitution and Trafficking (ECPAT), United Nations Children's Fund (UNICEF), Plan International, dan Save the Children; jurnal yang membahas isu tersebut; juga buku dan literatur lainnya yang berkaitan dengan social support serta human behavior and social environment. Fokus dari kajian ini adalah gambaran sistem dukungan sosial sebagai salah satu intervensi bagi korban ESKA. Pembahasan meliputi pentingnya sistem dukungan sosial bagi anak korban ESKA, peran sistem dukungan sosial yang terdiri dari keluarga/pengasuh, komunitas, serta lembaga serta peran pekerja sosial dalam menjembatani sumber daya-sumber daya yang ada demi kepentingan terbaik anak korban ESKA.

\section{PEMBAHASAN \\ Pentingnya Sistem Dukungan Sosial Bagi Korban ESKA}

Risiko dan kerentanan korban ESKA dapat memengaruhi persepsinya terhadap diri sendiri dan lingkungannya. Kurniasari (2016) membagi faktor risiko (risk factors) remaja korban eksploitasi seksual menjadi enam: (1) Perlakuan yang salah terhadap anak, seperti, tindakan kekerasan fisik, emosional, atau penelantaran anak yang menimbulkan kerentanan anak untuk mecari perlindungan dari kelompok sebaya; (2) Keluar dari sekolah, tidak memiliki keterampilan akademis sehingga anak tidak memiliki modal untuk masuk ke dunia kerja; (3) Bergaul dengan kelompok sebaya berisiko, memperkenalkan remaja terhadap perilaku anti-sosial seperti merokok dan meminum minuman keras; (4) Tidak ada keluarga atau figur orang dewasa lain sebagai sumber dukungan psikososial, sehingga dapat memengaruhi kemampuan anak mengelola trauma; (5) Terbatasnya faktor attachment antara anak dan orang tua pasca peristiwa kekerasan, membuat kehidupan emosi remaja rapuh; (6) Pengalaman hubungan seksual sejak dini, akibat terbatasnya informasi tentang kesehatan reproduksi.

Sistem dukungan sosial dapat berperan sebagai faktor perlindungan (protective factors) guna meminimalisasi dampak dari faktor risiko sehingga terbentuk resiliensi dalam diri anak. Resiliensi dapat didefinisikan sebagai kemampuan seseorang untuk berhasil menyikapi perubahan, kesulitan, atau risiko yang signifikan (Van Wormer, 2017). Seorang anak dapat dikatakan resilien ketika mereka bisa bertahan dan berkembang meskipun dengan keluarga dan kondisi sosial yang menantang dan penuh tekanan, termasuk, misalnya, orang tua yang tidak terkapasitasi dengan baik secara emosional dan kemiskinan yang ekstrem (Duncan \& Arntson, 2004).

Peristiwa yang mengancam jiwa anak, seperti menjadi korban eksploitasi seksual, dapat mengubah perilaku, menghambat atau mengganggu perkembangan, juga menunjukkan "gejala-gejala" dramatis, yang merupakan hasil dari tekanan emosional yang didapat (Duncan \& Arntson, 2004). Maka, sistem dukungan sosial 


\begin{tabular}{|c|c|c|c|c|}
\hline Share: Social Work Jurnal & VOLUME: 10 & NOMOR: 2 & HALAMAN: 57 - 63 & $\begin{array}{c}\text { ISSN: } 2339-0042(\mathrm{p}) \\
\text { ISSN: } 2528-1577(e) \\
\text { DOI: } 10.24198 / \text { share.v10i1.26896 }\end{array}$ \\
\hline
\end{tabular}

diperlukan sebagai agen sosialisasi. Sosialisasi adalah proses menginternalisasi pengetahuan, keterampilan, dan karakter yang memungkinkan mereka untuk berpartisipasi sebagai anggota efektif dari kelompok dan masyarakat (Berns, 2013). Perilaku atau nilai-nilai positif yang disosialisasikan bisa meminimalisasi-bahkan memulihkan-trauma serta meningkatkan wellbeing korban ESKA.

Wellbeing adalah kondisi positif seseorang ketika ia sedang berkembang (United Nations Children's Fund, 2018). Dalam pedoman operasional Mental Health and Psychosocial Support yang digarap oleh UNICEF, wellbeing anak dikategorikan menjadi tiga: (1) Personal wellbeing, meliputi pikiran dan emosi positif, seperti harapan, ketenangan, harga diri, dan kepercayaan diri; (2) Interpersonal wellbeing, yaitu memupuk hubungan, sense of belonging, dan kemampuan untuk menjadi dekat dengan orang lain; (3) Keterampilan dan pengetahuan, yaitu kemampuan untuk belajar, membuat keputusan positif, merespon tantangan hidup secara efektif, serta mengekspresikan diri. Dengan demikian, system dukungan sosial yang komprehensif akan dapat menjadi salah satu faktor terciptanya resiliensi dan well-being anak korban ESKA. Sistem dukungan sosial dari perspektif system berarti menggunakan sumber daya-sumber daya disekitar anak korban ESKA agar korban dapat mengintegrasikan hidupnya di lingkungan, serta lingkungan dapat menerima anak korban ESKA dan menghapus stigma yang ada di masyarakat mengenai anak korban ESKA. Sistem dukungan sosial bagi anak korban ESKA menjadi penting agar anak korban ESKA dapat melanjutkan kehidupannya dan berfungsi sosial secara maksimal dalam kehidupannya.

\section{Peran Sistem Dukungan Sosial pada Setiap Sumber Dukungan}

Anak-anak yang terjerumus ke dalam dunia eksploitasi seksual komersial merupakan korban. Hal ini perlu ditekankan sebelum melihat dan memberikan dukungan sosial kepada korban ESKA. Stigmatisasi masyarakat yang memperlakukan mereka sebagai penjahat seringkali membuat anak mengalami trauma dan enggan untuk kembali ke lingkungannya (ECPAT Internasional, 2006). Sistem dukungan sosial tidak akan terbentuk dan terlaksana dengan baik bila stigma seperti itu masih melekat di lingkungan. Oleh sebab itu, peran utama dari sistem dukungan sosial adalah menerima korban ESKA dengan menghilangkan stigma tersebut. Secara umum, dukungan sosial yang diberikan meliputi penerimaan kondisi biopsikososial korban, memberi akses dan kesempatan agar korban dapat berkembang dan meningkatkan keberfungsian sosialnya, serta melakukan tindak preventif untuk menghindari korban kembali terjerumus dalam eksploitasi maupun aktivitas berisiko lainnya.

Dukungan sosial yang bersumber dari keluarga, masyarakat dan lembaga sebagai sebuah sistem dukungan sosial memiliki peran masingmasing dalam memenuhi kebutuhan korban ESKA. Publikasi Child Welfare Information Gateway yang berjudul Human Trafficking and Child Welfare: $A$ Guide for Caseworkers (2017) mengkategorikan kebutuhan korban perdagangan anak.

1. Kesehatan fisik: Anak yang diperdagangkan sering mengalami kekerasan fisik, emosional, dan seksual, sehingga membutuhkan akses pelayanan medis.

2. Kesehatan perilaku (behavioral health): Anak membutuhkan pelayanan kesehatan perilaku yang dapat membantu mereka menangani gejala-gejala gangguan mental-seperti, Post Traumatic Stress Disorder, Panic Attack, Obsessive-Compulsive Disorder, Anxiety Disorder, Depressive Disorder (Williamson, Dutch, \& Clawson, 2010)—serta menjalankan kehidupan yang lebih sehat.

3. Tempat tinggal: Anak korban perdagangan membutuhkan tempat yang aman untuk ditinggali, mengingat latar belakang merekaseperti, keluarga yang belum siap untuk mengasuh anak korban perdagangan-yang bisa membuat mereka rentan.

4. Pendidikan: Setiap anak berhak mendapatkan pendidikan, namun, tidak semua korban perdagangan dapat menempuh pendidikan di sekolah formal, sehingga ada yang memilih untuk menempuh pendidikan non-formal.

5. Pekerjaan: remaja korban perdagangan mungkin membutuhkan bantuan ketika mencari pekerjaan, terutama jika mereka kekurangan pengalaman pekerjaan yang umum dan legal, belum mendapat ijazah sekolah menengah, atau hambatan ketika ada pengecekan latar belakang saat melamar pekerjaan.

6. Pelayanan hukum: Anak yang diperdagangkan membutuhkan pelayanan ketika berhadapan dengan hukum untuk melindungi mereka atau melakukan advokasi.

7. Kebutuhan lain: Kebutuhan ini meliputi keterampilan hidup dasar (seperti, membuka rekening tabungan dan menyimpan catatan medis) serta bantuan dari pihak yang dapat 
membimbingnya agar tidak kembali menjadi korban perdagangan manusia.

Berdasarkan kebutuhan-kebutuhan tersebut, setiap sumber dukungan dapat memberikan dukungannya bagi anak korban ESKA, agar mereka dapat melanjutkan hidup mereka setelah terbebas dari pengalaman ESKA.

\section{Dukungan Sosial oleh Keluarga atau Pengasuh}

Keluarga merupakan aspek penting dalam pembentukan kepribadian anak. Ketika proses sosialisasi yang dilakukan di keluarga tidak sempurna, anak cenderung tidak bisa bersosialisasi dengan baik di lingkungan yang lebih luas. Disfungsi keluarga menjadi salah satu alasan mengapa anak merasa tidak nyaman, sehingga ia memproyeksikan kebutuhan emosionalnya akan kenyamanan kepada teman sebaya atau orang lain di sekitarnya, yang bisa membawanya pada lingkungan negatif.

Pada situasi lain, ada anak yang memang sengaja dijadikan objek eksploitasi seksual oleh keluarganya. Ada pula keluarga yang tidak mau menerima kembali anaknya yang sudah menjadi korban eksploitasi seksual. Beberapa literatur menyatakan alasan mengapa anak bisa menjadi korban ESKA adalah karena ingin membantu perekonomian keluarga (Kurniasari, 2016). Dalam kondisi seperti ini, dibutuhkan intervensi pada keluarga untuk diberikan pemahaman terkait risiko ESKA dan bahayanya bagi pertumbuhan anak, baik kepada orang tua maupun anak itu sendiri. Selain itu, karena perekonomian keluarga menjadi faktor penyebab, diperlukan juga intervensi penyelamatan ekonomi keluarga. Sehingga dengan demikian, anak tidak lagi dikorbankan dengan alasan membantu perekonomian keluarga.

Jika keluarga atau pengasuh bisa membangun ikatan yang kuat dengan anak serta memberikan akses terhadap kebutuhan dasar seperti sandang, pangan, papan, dan pelayanan kesehatan, anak bisa bertahan lebih baik dalam kondisi-kondisi sulit (Al-Eissa, 1995). Membangun sense of belonging dan attachment dalam keluarga sehingga anak dan orang tua bisa lebih terbuka satu sama lain penting sebagai bentuk dukungan emosional. Hal ini dapat dilakukan dengan meningkatkan keterampilan komunikasi orang tua dan anak. Mendengarkan dan mengutarakan perasaan berdasarkan perspektif orang tua dan anak hingga terjadi kesepakatan tentang suatu hal merupakan beberapa aspek komunikasi yang dapat diasah bagi orang tua dan anak.

Namun, faktor ekonomi bisa menjadi salah satu penghambat terbentuknya dukungan sosial yang efektif dalam keluarga, malah meningkatkan kerentanan anak untuk terpapar pada eksploitasi seksual (ECPAT Internasional, 2006). Begitu pula akses anak untuk mendapat pendidikan yang lebih baik-sebagai tindak preventif untuk menghindari perilaku berisiko-serta pelayanan kesehatan dan pelayanan hukum yang memadai. Maka, di sini lah peran komunitas yang ada di lingkungan sekitar korban dibutuhkan untuk memberi dukungan sosial yang konsisten kepada keluarga atau pengasuh.

\section{Dukungan Sosial oleh Komunitas}

Anak dan remaja mempelajari banyak hal dari lingkungan sekitarnya. Dari tetangga, teman sebaya, guru, juga orang lain yang berinteraksi dengan anak di lingkungannya. Jaringan ini dapat disebut sebagai komunitas. Komunitas bisa memberi dukungan sosial berupa tindakan supportif, preventif, rehabilitatif (Berns, 2013).

Berbagai inisiatif intervensi dilakukan dalam tingkat komunitas, salah satunya terkait perlindungan anak, yang biasa disebut sebagai Community-Based Child Protection Mechanism (CBCPM), atau Perlindungan Anak Terpadu Berbasis Masyarakat (PATBM). Dalam laporan Plan International (2015), CBCPM memiliki beberapa peran, antara lain, meningkatkan pemahaman masyarakat tentang perlindungan anak, mengidentifikasi anak atau keluarga berisiko, menyediakan dukungan keluarga dan parenting, melakukan mediasi kasus, serta melakukan rujukan kasus pada pihak yang berwenang. $\mathrm{Di}$ Indonesia, Kementerian Pemberdayaan Perempuan dan Perlindungan Anak juga memiliki panduan PATBM sendiri pada tiga level; anak, keluarga, dan komunitas (Kemenppa, n.d).

Peningkatan pemahaman tentang ESKA dapat dilakukan oleh pekerja sosial komunitas. Pelibatan figur berpengaruh di komunitas, seperti kepala desa atau tokoh agama, penting agar penyebaran pemahaman lebih menyeluruh. Kesadaran akan faktor-faktor risiko ESKA di komunitas bisa meningkat, serta stigmatisasi terhadap korban ESKA juga dapat dihilangkan. Membangun ruang publik yang ramah anak juga harus dilakukan. Hal ini meliputi akses terhadap pendidikan, kesehatan, kesempatan untuk bermain, mendapat perlindungan, serta pemenuhan hak-hak anak lainnya.

Anak yang terkena eksploitasi seksual membutuhkan pelatihan keterampilan hidup, atau life skill. Hal ini dikarenakan banyak anak yang terlibat dalam eksploitasi seksual komersial sebelum menuntaskan pendidikannya, sehingga 
mereka kekurangan keterampilan finansial, pendidikan, kepemimpinan, self-efficacy, danbagi beberapa anak-tidak memiliki aktivitas atau hobi yang bermakna (Ijadi-Maghsoodi, Cook, Barnert, Gaboian, \& Bath, 2016). Maka, komunitas bisa menyediakan kesempatan untuk meningkatkan kapasitas anak agar bisa memiliki keterampilan khusus ketika masuk ke dunia kerja.

\section{Dukungan Sosial oleh Lembaga}

Ketika korban ESKA membutuhkan bantuan profesional dari segi psikologis maupun legal, lembaga dapat menjadi jembatan yang memiliki referensi rujukan. Proses hukum atau proses pemulihan trauma korban dapat memakan waktu lama, sehingga, perlu ada konsistensi dalam dukungan sosial yang diberikan oleh lembaga.

Objektifikasi terhadap perempuan, diskriminasi, stigmatisasi, dan victim blaming adalah beberapa alasan mengapa kekerasan berbasis gender masih marak terjadi di masyarakat, termasuk kepada anak-anak. Beberapa tradisi adat juga masih memperbolehkan praktik eksploitasi seksual anak. Bahkan, di beberapa negara, hal ini disamarkan menjadi praktik keagamaan (ECPAT Internasional, 2006). Berdasarkan hal tersebut, Lembaga-lembaga penyedia layanan baik itu intervensi kepada masyarakat, advokasi maupun aksi sosial perlu mensosialisasikan perubahan nilai yang berlaku di masyarakat mengenai perempuan dan korban ESKA.

Budaya, sebagai nilai atau praktik yang sudah melekat dan mengakar di masyarakat, memiliki pengaruh besar tidak hanya dalam komunitas, tetapi keluarga dan diri sang anak. Peningkatan pemahaman dan kesadaran masyarakat luas tentang ESKA tidak akan cukup jika tidak didukung oleh payung hukum. Penyusunan kebijakan yang melindungi korban ESKA memang tidak memiliki dampak langsung. Namun, hal ini bisa menjadi suatu bentuk dukungan sosial oleh Lembaga yang peduli dan menyediakan layanan bagi para korban ESKA.

Kesediaan dan pengetahuan masyarakat untuk melaporkan kasus ESKA kepada pihak berwajib ESKA sangat diperlukan. Ini adalah salah satu bentuk kepedulian bagi korban. Dukungan lain bisa diberikan melalui sumbangan material yang dapat menunjang perkembangan dan pemulihan trauma korban, maupun jasa, seperti menjadi relawan yang mengajarkan keterampilan vokasional.

\section{Peran Pekerja Sosial dalam Merancang Sistem Dukungan Sosial}

Untuk memenuhi kebutuhan-kebutuhan anak korban ESKA sebagaimana yang telah diuraikan sebelumnya, diperlukan sinergi antara keluarga atau pengasuh, komunitas, serta Lembaga-lembaga yang pelayanannya diperlukan oleh anak korban ESKA. Pekerja sosial sebagai seorang professional yang berfokus pada perlindungan dan kesejahteraan anak, memiliki mandat untuk bekerja dengan anak korban ESKA, sesuai dengan UU. Pekerja sosial berperan untuk merancang intervensi-dalam hal ini, sistem dukungan sosial-sekaligus men-supervisi terwujudnya sistem dukungan sosial agar kualitas dukungan dan keberlanjutannya dapat memastikan anak korban ESKA mendapatkan kebutuhan-kebutuhannya agar dapat sejahtera dan resilien.

Korban ESKA secara individu dapat diintervensi langsung oleh pekerja sosial yang berfokus pada bidang kesejahteraan anak. Mengingat rentannya korban serta ketidakstabilan kondisi fisik maupun emosionalnya, pekerja sosial dapat melakukan pendekatan berbasis TraumaInformed Care. Pelayanan ini mengandung tiga komponen utama; menyadari gejala-gejala trauma, memahami dampak dari trauma masa lalu terhadap kehidupan individu, kemudian menggabungkan pemahaman tersebut ke dalam praktik untuk memberdayakan dan menghindari pengulangan trauma individu (Elliott, Bjelajac, Fallot, Markoff, \& Reed, 2005).

Untuk mewujudkan perlindungan anak, pekerja sosial harus berusaha membangun hubungan dengan semua system (Webb, 2019) yang berada di lingkaran kehidupan anak korban ESKA. Semua intervensi yang hendak dilakukan oleh pekerja sosial harus berdasarkan pada kebutuhan klien berdasarkan sudut pandang anak korban ESKA sebagai klien. Sehingga hanya dengan begitu, intervensi pekerja sosial dapat efektif dan efisien.

Pekerja sosial professional dapat berperan sebagai fasilitator, broker maupun advokat dalam bekerja dengan anak korban ESKA. Agar menjadi komprehensif dan terpadu, pekerja sosial perlu bekerja sama dengan profesi lain seperti dokter, polisi, Lembaga Pendidikan, dan lain-lain. Dengan dibangunnya system dukungan sosial bagi anak korban ESKA oleh pekerja sosial, tujuan yang ingin dicapai adalah kesejahteraan dan resiliensi anak korban ESKA, keluarga yang penuh dukungan dan masyarakat yang lebih inklusif dan menerima keberadaan anak korban ESKA. 


\section{KESIMPULAN DAN SARAN}

Anak yang mengalami eksploitasi seksual komersial memiliki kerentanan tinggi pada aspek biologis, psikologis, maupun sosialnya. Dalam jangka panjang, peristiwa tersebut juga bisa berdampak pada perkembangannya. Untuk itu, perlu dibangun lingkungan yang mendukung sebagai faktor protektif yang dapat meminimalisasi, atau bahkan menghilangkan, faktor risiko yang ada dalam diri dan lingkungan sekitar korban ESKA.

System dukungan sosial bagi anak korban ESKA perlu dibangun secara komprehensif mulai dari system mikro (keluarga), mezzo (masyarakat) hingga makro (Lembaga). Dukungan dari keluarga dapat berupa pemberian kasih saying dan keterbukaan berkomunikasi serta membangun kelekatan antara orang tua dengan anak. Di sisi lain, dukungan dari masyarakat dapat diberikan dalam bentuk pengakuan anak korban ESKA sebagai anggota masyarakat dan menghilangkan stigma negative mengenai anak korban ESKA. Kedua system tersebut dapat menjadi lebih terpadu dengan dukungan dari Lembaga melalui dukungan pemenuhan kebutuhan-kebutuhan yang diperlukan oleh anak korban ESKA. Agar layanan bagi anak korban ESKA bersifat komprehensif dan terpadu, diperlukan sinergi antar tingkatan dalam sistem dukungan sosial. Baik keluarga, komunitas, hingga lembaga, semua memiliki korelasi yang erat dalam memberi dampak bagi perkembangan anak. Penerimaan, perlindungan, serta pemberdayaan menjadi tiga kunci utama dalam sistem dukungan sosial bagi korban ESKA. Tiap tingkatan dukungan sosial juga harus ditingkatkan kualitasnya dengan cara memberikan peningkatan kapasitas serta pemberdayaan yang berkelanjutan oleh para pekerja sosial.

\section{UCAPAN TERIMA KASIH}

Penulis mengucapkan terima kasih kepada seluruh pihak yang telah membantu penyusunan tulisan ini, terutama civitas Departemen Kesejahteraan Sosial, Fakultas IImu Sosial dan Ilmu Politik, Universitas Padjadjaran.

\section{DAFTAR PUSTAKA}

Al Eissa, Y. A. (1995). The Impact of the Gulf Armed Conflict on the Health and Behavior of Kuwaiti Children. Social Science And Medicine, 41(7), 1033-1037.

Berns, R. (2013). Child, Family, School, Community: Socialization and Support. California: Wadsworth, Cengage Learning.

Child Welfare Information Gateway. (2017). Human Trafficking and Child Welfare: A
Guide for Caseworkers. Bulletins for Professionals.

Dalla, R. L., Xia, Y., \& Kennedy, H. (2003). You Just Give Them What They Want and Pray They Don't Kill You: Street Level Sex Workers' Reports of Victimization, Personal Resources and Coping Strategies. Violence Against Women, 9(11), 1367-1394.

Dinwiddie, S., Heath, A. C., Dunne, M. P., Bucholz, K. K., Madden, P. A., Slutske, W. S., . . . Martin, N. G. (2000). Early Sexual Abuse and Lifetime Psychopathology: A co-twincontrol study. Psychological Medicine(30), 41-52.

Duncan, J., \& Arntson, L. (2004). Children in Crisis: Good Practices in Evaluating Psychosocial Programming. Save the Children Federation, Inc.

ECPAT Indonesia. (2019, June 10). Catatan Pemantauan Media ECPAT 2018. Retrieved from ECPAT Indonesia: https://ecpatindonesia.org/publikasimedia/catatan-pemantauan-media-ecpat2018/

ECPAT Internasional. (2006). Tanya \& Jawab tentang Eksploitasi Seksual Komersial Anak. Jakarta, Indonesia: RESTU Printing.

Elliott, D., Bjelajac, P., Fallot, R., Markoff, L., \& Reed, B. (2005). Trauma-informed or trauma-denied: principles and implementation of trauma-informed services for women. Journal of community psychology, 33(4), 461-477.

Goatley, E. (2012). A Study of the Impact of Perceived Individual Stigma, Social Stigma and Social Support on Treatment Seeking Behaviors of Victims of Sexual Exploitation in Georgia. ETD Collection for AUC Robert W. Woodruff Library.

Hutchison, E. (2015). Dimensions of Human Behavior: Person and Environment. California: SAGE Publications.

Ijadi-Maghsoodi, R., Cook, M., Barnert, E. S., Gaboian, S., \& Bath, E. (2016). Understanding and Responding to the Needs of Commercially Sexually Exploited Youth: Recommendations for the Mental Health Provider. Child and Adolescent Psychiatric Clinics of North America, 25(1), 107-122.

KemenPPA. (n.d.). Buku Saku Aktivis/Kader Perlindungan Anak Terpadu Berbasis Masyarakat (PATBM). Jakarta: Kementerian PPA RI. 


\begin{tabular}{|c|c|c|c|c|}
\hline Share: Social Work Jurnal & VOLUME: 10 & NOMOR: 2 & HALAMAN:57-63 & $\begin{array}{c}\text { ISSN: 2339-0042 (p) } \\
\text { ISSN: 2528-1577 (e) } \\
\text { DOI: 10.24198/share.v10i1.26896 }\end{array}$ \\
\hline
\end{tabular}

KPAI. (2019, Oktober 30). KPAI: Anak Korban Perdagangan Orang Butuh Layanan Rehabsos. Retrieved Januari 26, 2021, from www.kpai.go.id: https://www.kpai.go.id/berita/kpai-anakkorban-perdagangan-orang-butuhlayanan-rehabsos

Kurniasari, A. (2016). Faktor Risiko Anak Menjadi Korban Eksploitasi Seksual (Kasus di Kota Surabaya). Sosio Konsepsia, 5(3), 113-134.

Liyawati, I. D., \& Imron, A. (2016). Praktik Inklusi Sosial Penanganan Korban Anak yang Dilacurkan (AYLA) di Surabaya. Paradigma, 04(03), 1-9.

Mardalis. (1999). Metode Penelitian Suatu Pendekatan Proposal. Jakarta: Bumi Aksara.

Payne, M. (2014). Modern Social Work Theory. London, UK: Palgrave Macmillan.

Plan International. (2015). Community-Based Child Protection Mechanisms: Global Synthesis Report of Plan International's Support to CBCPMs. United Kingdom: Plan International Headquarters.

Sugiharti, S. (2017). Peran INGO "Save the Children" dalam Menangani Kasus Eksploitasi Seksual Komersial Anak di Indonesia Tahun 2010-2015.

United Nations Children's Fund. (2014). Hidden in Plain Sight: $A$ statistical analysis of violence against children. New York: UNICEF.

United Nations Children's Fund. (2018). Operational Guidelines on CommunityBased Mental Health and Psychosocial Support in Humanitarian Settings: Threetiered Support for Children and Families (Field Test Version). New York: UNICEF.

Van Wormer, K. (2017). Human Behavior and the Social Environment, Micro Level: Individuals and Families. New York: Oxford University Press.

Walsh, J. (2015). The Psychosocial Person: Relationships, Stress and Coping. In E. D. Hutchinson, Dimensions of Human Behavior: Person and Environment (pp. 268 - 318). Los Angeles: Sage Publications.

Webb, N. B. (2019). Social Work Practice with Children 4th Edition. New York: The Guilford Press.

Williamson, E., Dutch, N. M., \& Clawson, H. J. (2010). Evidence-Based Mental Health Treatment for Victims of Human Trafficking. Washington D.C.: Office of the Assistant Secretary for Planning and
Evaluation, US Department of Health and Human Services. 